\title{
SJoP
}

\section{What I wish I had said}

\section{STEVEN FRASER}

The Scottish Journal of Performance

Volume 5, Issue 1; April 2018

ISSN: 2054-1953 (Print) / ISSN: 2054-1961 (Online)

Publication details: http://www.scottishjournalofperformance.org

To cite this article: Fraser, S., 2018. What I wish I had said. Scottish Journal of Performance, 5(1): pp.171-177.

To link to this article: http://doi.org/10.14439/sjop.2018.0501.16

(C) $\begin{aligned} & \text { This work is licensed under a Creative Commons } \\ & \text { Attribution } 4.0 \text { International License. See } \\ & \text { http://creativecommons.org/licenses/by/4.0/ for details. }\end{aligned}$
BY




\section{What I wish I had said}

STEVEN FRASER

DOI: 10.14439/sjop.2018.0501.16

Publication date: 6 April 2018
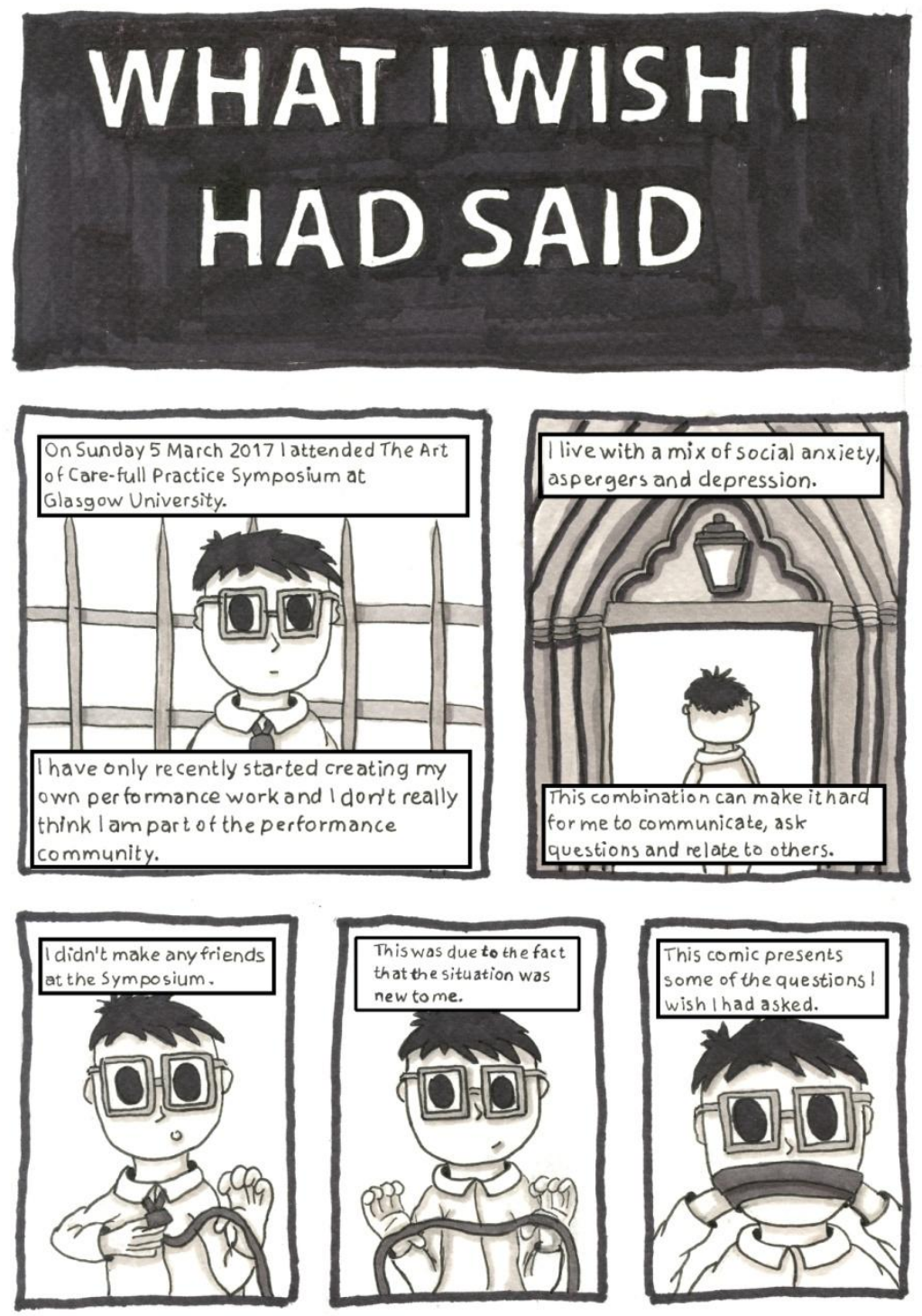


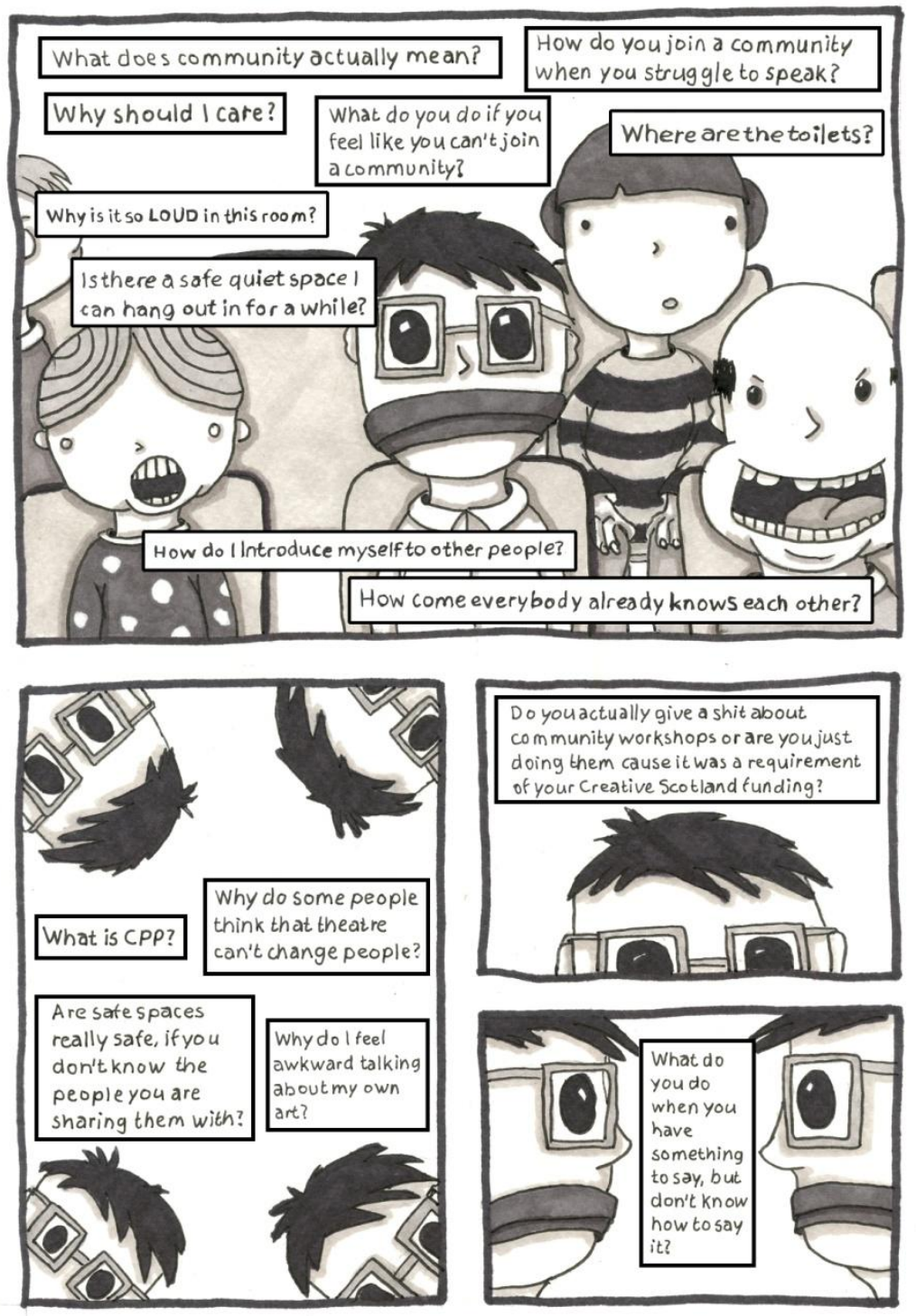




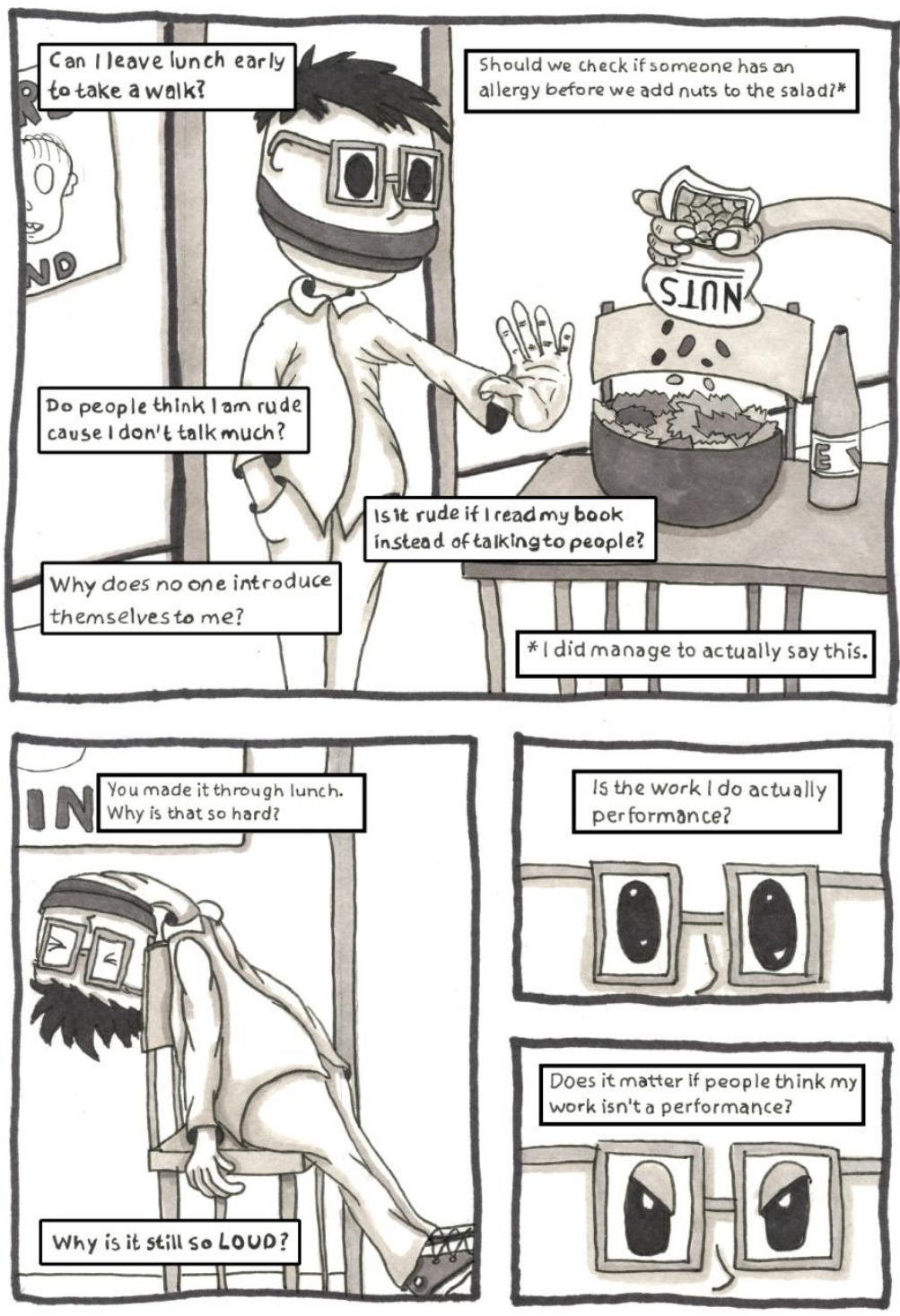










\section{About the author}

STEVEN FRASER is a writer and artist who has a background in theatre, comic books and animation. His work focuses on mental health and autism and has been staged at The Pleasance Theatre, Hidden Door Festival, Rich Mix London and New Diorama Theatre London. His work has received Creative Scotland Funding, a Tom McGrath Small Grant Award and a Starter for Ten Award from the National Theatre of Scotland. 